\title{
DEVELOPMENT OF CASTING PATTERN USING RAPID PROTOTYPING
}

\author{
R. R. Malagi ${ }^{1}$, Mahendra .S.B ${ }^{2}$, Anil Pol ${ }^{3}$, Prasad Raikar ${ }^{4}$ \\ ${ }^{1}$ Professor, Dept of Product Design and Manufacturing, Dept.of PG Studies VTU Belgaum \\ ${ }^{2}$ M.Tech Scholar, Product Design and Manufacturing Dept.of PG Studies VTU Belgaum \\ ${ }^{3}$ Assistant professor, Dept of Product Design and Manufacturing, Dept.of PG Studies VTU Belgaum \\ ${ }^{4}$ Assistant professor, Dept of Product Design and Manufacturing, Dept.of PG Studies VTU Belgaum
}

\begin{abstract}
Be it a product based or process based industry, quality is by far the most important characteristic by a customer. To improve the quality in foundries around the world, CAD/CAM and other packages have been used as a tool to achieve quality and productivity. In this concern, the use of Rapid Prototyping (RP) is not yet fully practiced in foundries. This research provides a detail study of the fabrication of a master pattern (step bar) of casting using rapid prototyping technique as well as presenting its scope and benefits compared to the current practices. The main objective of this paper is to enlighten the foundry engineers to make use of rapid prototyping technology (fused deposition modeling), to reduce the lead-time in the production of accurate sand castings of an acceptable quality and dimensional accuracy. This work extends in its research to study microscopic observation of casting and mechanical properties of casting model. Apart from that, it also focuses upon the comparative study of surface roughness of the RP model and wooden model.
\end{abstract}

Keywords — Fused deposition modeling, Master pattern, Rapid Prototyping, Sand casting.

\section{INTRODUCTION}

Prototypes are very important for realization of concepts in design, manufacturing and analysis. Prototyping is one of the most essential parts of product development and manufacturing cycle required for assessing the form, fit and functionality of a design before a significant investment is made. Apparently, a dominant technology for producing physical models for testing and evaluation purposes has been rapid prototyping (RP).Fused deposition modeling (FDM) is an additive technology suite for producing prototypes and final parts with complex geometries. FDM has the advantage of providing several ABS materials and is clearly the most usual in this technology [1,2]. In a conventional metal casting development cycle, which consumes several months for producing the first good sample, especially for replacing an existing part, presents an immediate opportunity for integration of advanced computer aided procedures and rapid prototyping (RP) with conventional practices [3]. It is observed that the major portion of the lead-time of casting development cycle, especially in the case of geometrically complex parts required in small order quantity, is spent on tooling development [4], modifications, trials and inspection. This leads to severe compromise in terms of time and cost competitiveness. This work proposes an integrated approach involving $\mathrm{CAD} / \mathrm{CAM}$ simulation such as rapid prototyping, process and metal casting to achieve speed and economy in developing casting model [5]. The present work focuses on a techno-economic comparison of the accurate sand castings quality, surface roughness, microscopic observation of casting and impact testing of casting model. The discussion is made on the development of sand casting using aluminum alloy, both by conventional (wooden) as well as RP processing route.

\section{DESIGN AND FABRICATION}

The maintaining of close dimensional tolerance in a casting is affected by many factors such as master pattern, casting process, pouring material and their alloys. A specified tolerance and surface quality of the casting depends on the quality of the pattern.

Generally in foundries, the pattern are developed by wood and metal, this patterns don't offer achieving a exact shapes ,specified tolerance and surface quality, prone to fungus attack and corrosion. More over some patterns require the special coating to increases the life of the pattern.

To overcome this limitation introduces the alloy patterns, but the alloy pattern cost is more than that of wood/metal master pattern. Recently all this limitation of the wood/metal/alloy master patterns has lead to development of the ABS patterns.

The ABS is an ideal material for conceptual prototyping through design verification through directs, digital manufacturing such as rapid prototyping. The ABS pattern has more life then wooden pattern because of high density, rigidity and low shrinkage compared to the wooden pattern.

Table 1 The Properties of ABS-M30 and Teak Wood Pattern [1]. 


\begin{tabular}{|l|l|l|}
\hline Properties & ABSM30 & Teak wood \\
\hline $\begin{array}{l}\text { Ultimate } \\
\text { tensile } \\
\text { strength } \\
\text { (MPa) }\end{array}$ & 40 & $95-155$ \\
\hline $\begin{array}{l}\text { Compressive } \\
\text { strength (MPa }\end{array}$ & 42 & $49-91$ \\
\hline $\begin{array}{l}\text { Thermal } \\
\text { conductivity }\end{array}$ & 0.2 & 0.19 \\
\hline $\begin{array}{l}\text { Poisson's } \\
\text { ratio }\end{array}$ & 0.35 & 0.42 \\
\hline $\begin{array}{l}\text { Operating } \\
\text { Temperature } \\
\text { (C }\end{array}$ & 60 & 30 \\
\hline Density(kg/m3 & 1024 & $630-720$ \\
\hline Shrinkage & 0.1 & 0.6 \\
\hline
\end{tabular}

Rapid prototyping is process that automatically creates a physical model from a 3D CAD data in a short period of time. The model is build layer by layer. In general, the rapid prototyping involves following steps:

1. Creation of CAD models of all components

2. Conversion of CAD models to STL format

3. Slicing of STL file into thin cross-sectional layers

4. Layer by layer construction of the models

5. Cleaning and finishing of the RP models

The RP model is created by varies modeling CAD software packages such as AUTO CAD, solid edge, solid works, CATIA etc. Then, convert the CAD file into STL format here the CAD file has to be stored in the STL format.. This format represents a three- dimensional surface as an assembly of planar triangles "like the facets of a cut jewel". The file contains the coordinates of the vertices and the direction of the outward normal of each triangle. Since, STL file uses planar elements, it cannot represent curved surface exactly. Increasing the number of triangles improve the approximation so designer must balance accuracy with manageability to produce a useful STL file .Since the STL format is universal, this is identical for all of the RP build techniques.

In the Fused Deposition Modeling" INSIGHT" software is used to slice the STL files. Each RP machine manufacturer supplies their own proprietary slice software. In this software $\mathrm{m}$, STL model is sliced into a number of layers from $0.01 \mathrm{~mm}$ to $0.7 \mathrm{~mm}$ thick, depending on the build technique. The program may also generate auxiliary structures to support the model during the build. The "INSIGHT" software calculates the time taken to build the parts and amount of building material and the support material needed for building the model.

In this study Fused Deposition Modeling (FDM) is used to fabricate the step bar master patterns. A plastic filament (ABS) is unwound form coil and supplies material to an extrusion nozzle. The nozzle is heated to melt the plastic and has a mechanism which allows the flow of the melted plastic to be turned on and off. As the nozzle is moved over the table in the required geometry, it deposits a thin of extruded plastic to from each layer, FDM requires 6 slice of $0.178 \mathrm{~mm}$ to complete $1 \mathrm{~mm}$ thickness of the part. The entire system is contained within a chamber which is held at a temperature just below the melting point of the plastic

The final step is post processing .This step involves remove the prototype from machine and detaching the supports, also it requires minor cleaning and surface treatment.

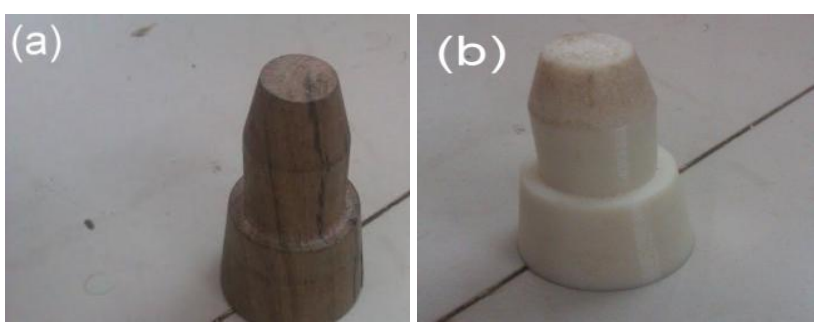

Fig1. Master Pattern of Step Bar casting (a) Wooden Material (b) ABS material

\section{RESULTS AND DISCUSSION}

Conventionally step bar master pattern is manufactured with reference to the casting drawing refereed by the foundry people and based on those drawings the wooden pattern is developed manually by some conventional method. Conventional method includes the hand cutting tool, chisel, and some different saws, etc. In another hand ABS pattern is developed by RP (FDM).

Table2: Lead Time and Cost Comparison for Conventional Method with RP method

\begin{tabular}{|l|l|l|}
\hline $\begin{array}{l}\text { Production } \\
\text { details }\end{array}$ & $\begin{array}{l}\text { Conventional } \\
\text { method }\end{array}$ & $\begin{array}{l}\text { Rapid } \\
\text { prototyping }\end{array}$ \\
\hline Design time & $2 \mathrm{hr}$ & $2 \mathrm{hr}$ \\
\hline $\begin{array}{l}\text { Fabrication } \\
\text { time }\end{array}$ & $2.5 \mathrm{hr}$ & $1.4 \mathrm{hr}$ \\
\hline Man hours & 6 & 3 \\
\hline Total time & $4.5 \mathrm{hr}$ & $3.4 \mathrm{hr}$ \\
\hline $\begin{array}{l}\text { Number of } \\
\text { casting } \\
\text { pattern }\end{array}$ & $40-60$ & $300-450$ \\
\hline $\begin{array}{l}\text { Total cost } \\
\text { of pattern } \\
\text { in rupees }\end{array}$ & 200 & 450 \\
\hline
\end{tabular}

The lead time comparison of fabrication of master patterns through conventional and RP technology Shows,66\% of reduction in the lead time obtained from RP.

The compared dimensions of the fabricated of both ABS and wood master patterns of aluminum sand castings were observed. Based on the observation, of the dimensional deviation between the fabricated ABS and wooden pattern edge, the wooden patterns were not sharp than the ABS patter. If the production is of small size, it is negligible. In the mass production there is loss in cost, since casting model need a secondary process for wooden master pattern. 
The ABS master patterns life is more than the wooden master pattern because the ABS material has high density and rigidity than wood. The ABS patterns are used to produce $300-450$ casts per pattern; in other hand wooden pattern can produced 40-60 casts per pattern.

A microscopic observation is made to understand the surface quality of both casting models. The ABS and wooden pattern photomicrographs are obtained at $2 \mathrm{X}$ magnification by "Nikon microscope LV150" with clemex image analyser. The microstructure consists eutectic silicon needles dispersed in the matrix of dendrites of aluminum solid solution. Its shown that the pattern material is doesn't affecting the casting microstructure.

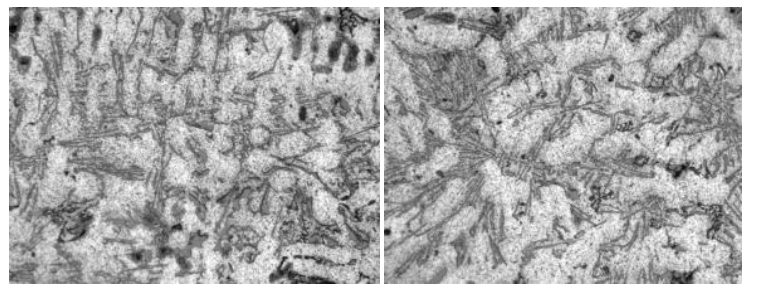

(a)

(b)

Fig.2 photo micrographs obtained at $2 \mathrm{X}$ magnification (a) ABS pattern (b) wooden pattern

The comparison of the surface roughness of both ABS and wood patterns are conducted by "MITUTOYO", surface roughness tester is used over a distance of $4 \mathrm{~mm}$ at two location on the vertical wall. The graphs shows, ABS pattern $(\mathrm{Ra}=2.75 \mu \mathrm{m})$ has better surface finish than the wood pattern $(\mathrm{Ra}=4.05 \mu \mathrm{m})$.
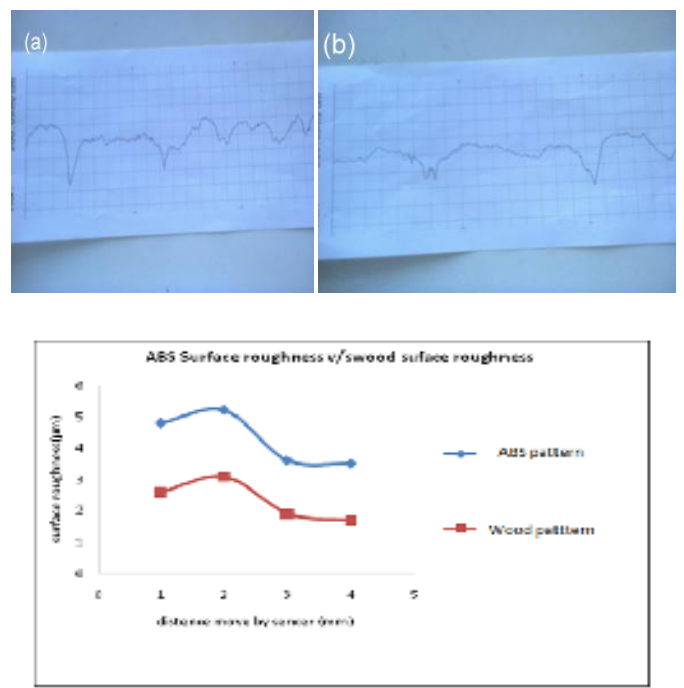

Fig.3 Graphs of Obtained by MITUTOYO surface roughness tester. (a) ABS Pattern (b) Wooden Pattern After casting of ABS patterns and wooden pattern samples are checked for the mechanical properties (IMPACT TEST). The charpy impact test, also known as the charpy V-notch test, is a standardized high strain - rate test which determines the amount of energy absorbed by a material during fracture. The testing model is shown in fig4.

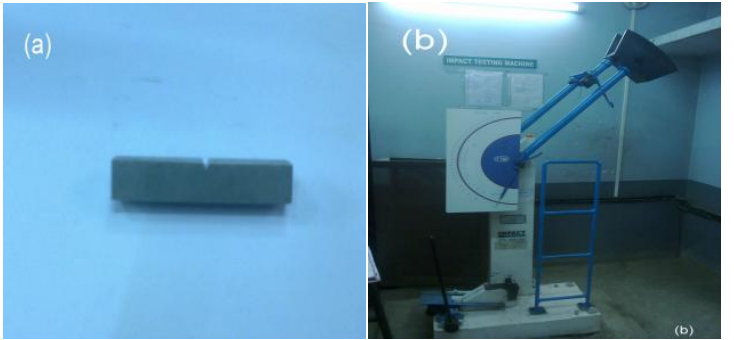

Fig4. (a) Impact test specimen (b) impact test machine

Impact test is carried out on $10 \mathrm{~mm} \times 10 \mathrm{~mm} \times 55 \mathrm{~mm}$ test pieces with a V- notched angle $45^{\circ}$ using a fully instrumented impact testing machine at $26^{\circ} \mathrm{C}$ while maintaining a uniform striking velocity.

The impact strength of both ABS and wooden pattern is same ("2J"). This shows poring material aluminum is proper dispersed in both patterns.

\section{CONCLUSIONS AND FUTURE SCOPE}

In the present study, the use of rapid prototyping technology in foundries is enhanced. As initial study, RP pattern is generated by using CAD model of the test specimen as an input and used to generate a casting. In order to get comparison, a casting is manufactured from a wooden pattern. The casted specimen has been tested for impact strength and surface properties. From the obtained experimental results, it is found that there is no much variation in the impact strength of the casted specimen obtained by both wooden and RP patterns. Similarly there small variation in surface property of casting and it is found that the surface finish of casting obtained by RP pattern is better than wooden pattern casting. In order to verify the usability of RP in foundry, the time and cost required to prepare the RP and wooden pattern is noted.

Here it is found that the time taken to make casting pattern by wood will increase as the complexity of the model increases. The choice of wood to make good pattern will also be difficult and surface finish of pattern depends on the workable properties of the wood, which intern affects the surface quality of the casting. The use of R.P model will solve all these problems. The time required to make CAD model and building time of the R.P. model is the only time required for making the model. By using R.P. method it is possible to make any complex pattern in lesser time, compared to conventional method, where the requirement of skilled operator is very essential.

The rapid prototyped part must be able to withstand the chemicals in the sand, be abrasion resistant and be able to withstand the ramming forces that are applied to pack the sand. Unlike many other rapid prototyping technologies, FDM meets these requirements with its $\mathrm{ABS}$ material. Results of this research work the CAD/CAM technology. 


\section{REFERENCES}

[1]. Rajashekar Patil, S. Mohan Kumar, E. Abhilash" Development of Complex Patterns:Scope and Benefits of Rapid Prototyping in Foundries" International Journal of Engineering and Innovative Technology (IJEIT) Volume 1, Issue 4, April 2012

[2]. A. Pranjal, B. Prof. A. M. Kuthe "Feasibility Study of manufacturing using Rapid Prototyping: FDM Approach" Proceedings of the 5thManufacturing Engineering Society International Conference - Zaragoza - June 2013

[3]. Dr. B. Ravi; (2000). "CAD/CAM Revolution for Small and Medium Foundries" 48th Indian Foundry Congress, Coimbatore

[4]. Akarte, M.M. and B. Ravi, "RP/RT Route Selection for Casting Pattern Development", 19th AIMTDR, Chennai, Dec 2000.

[5]. Sunil Jauhar, K. M. Asthankar\& A.M. Kuthe " Cost benefit analysis of Rapid Manufacturing in Automotive Industries" Advances in Mechanical Engineering and its Applications (AMEA) 181 Vol. 2, No. 3, 2012, ISSN 21676380 Copyright (C) World Science Publisher, United States [6]. Gefang Wang, Wenbin Cao, Guoshun Chen, Gang Niu, and Dong Zhang Mechanical Technology Research Institute, Mechanical Engineering College, Shi Jiazhuang, China 2012 3rd International Conference on System Science, Engineering Design and Manufacturing Informatization9781-4673-0915-8/12/\$31.00 @2012 IEEE

[7]. S. H. Masood, W. Rattanawong and P. Iovenitti, Part Build Orientations Based on Volumetric Error in Fused Deposition Modeling. Int J Adv Manuf Technol (2000) 16:162-168 02000 Springer-Verlag London Limited. Industrial Research Institute Swinbume, Swinbume University of Technology, Melbourne, Australia

[8]. C. W. Lee, C. K. Chua , C. M. Cheah, L. H. Tan, C. Feng,Rapid investment casting: direct and indirect approaches via fused deposition modeling. Int J Adv manuf Technol (2004) 23: 93-101_ Springer-Verlag London Limited 2003 